\title{
EDUCAÇÃO EM QUATRO DIMENSÕES: AS COMPETÊNCIAS QUE OS ESTUDANTES DEVEM TER PARA ATINGIR O SUCESSO
}

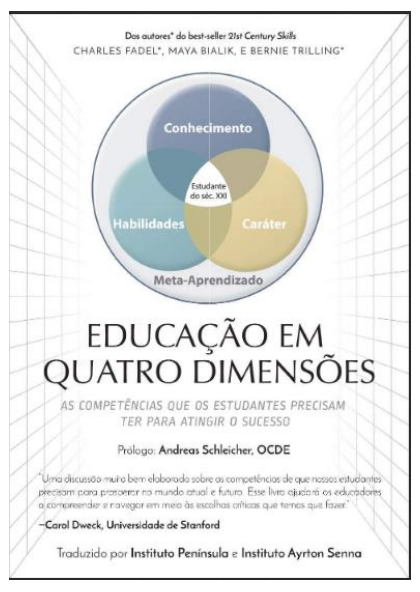

FADEL, Charles; BILIAK, Maia; TRILLING, Berning. Educação em quatro dimensões: as competências que os estudantes precisam ter para atingir sucesso. Trad. Lilian Bacich. São Paulo, SP: Instituto Ayrton Sena, 2016. 161 p. ISBN 978-85-623228-37-4

\section{Elisabete Cerutti ${ }^{1}$}

Esta resenha apresenta considerações acerca da obra "Educação em quatro dimensões:

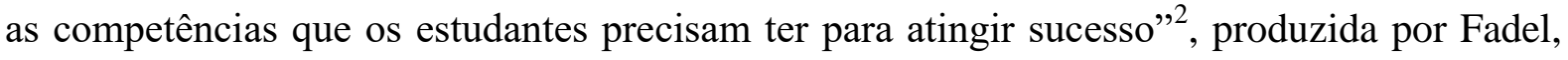
Charles; Biliak, Maya e Trilling, Bernie. O livro foi publicado em 2015 pela Center for Curriculum Redesign, EUA, traduzido para português e publicado no Brasil em novembro de 2016, sob revisão técnica de Lilian Bacich, em parceria com o Instituto Ayrton Sena. O livro apresenta oito capítulos, tendo Prefácio e Introdução que versam sobre a problematização que, ao longo da obra, possibilita o pensar sobre o que o estudante deve aprender para melhor preparar-se para o Século XXI, trazendo questões em evidência: "como preparamos nossos estudantes para os empregos que realmente existirão quando eles se graduarem?" Fadel, Biliak e Trilling, 2015, p.30). Nesse âmbito, descrevem as competências necessárias expostas nos currículos, a compreensão do caráter, as habilidades, a meta cognição e descortinar respostas para a relação frutífera entre educação, tecnologias, criatividade e pensamento crítico.

Em seu prefácio, o Diretor de Educação e Habilidades da Organização para a Cooperação e Desenvolvimento Econômico, OCDE, Andreas Schleicher, ressalta a importância das instituições educativas trabalharem na perspectiva de preparar o indivíduo para as mudanças que estão ocorrendo numa velocidade nunca vista antes. Estamos

\footnotetext{
${ }^{1}$ Universidade Regional Integrada do Alto Uruguai e das Missões. E-mail: beticerutti@ uri.edu.br - ORCID: http://orcid.org/0000-0002-3467-5052

${ }^{2}$ Disponível em: <http://www.institutoayrtonsenna.org.br/arquivos/Educacao-em-quatro-dimensoes.pdf> . Acesso em: 23 fev. 2017.
}

Submetido em: 23-02-2017 / Aceito em: 04-03-2017 / Publicado em: 14-04-2017

\begin{tabular}{l|l|l|l|l|l|l} 
(C) Rev. Inter. Educ. Sup. & Campinas, SP & v.3 & n.1 & p.245-248 & jan./abr. 2017 & ISSN $2446-9424$ \\
\hline
\end{tabular}


considerando o uso de tecnologias, ainda não apresentadas para a resolução de problemas que ainda surgirão, isto é, explorar o que conhecemos e aplicar em situações novas. Desse modo, requer uma educação mais focada na criatividade, comunicação, pensamento crítico e uso de tecnologias para soluções a uma humanidade sustentável e por, isso, com qualidade de caráter. Para isso, o meta-aprendizado, cujo conceito ocorre numa reflexão sobre si mesmo, propõe que o indivíduo se adapte ao que está vivenciando e continue aprendendo para atingir seus objetivos. Aspectos presentes na Introdução, alertam para esses desafios "o mundo para qual a educação foi planejada não existe mais, e mesmo que fosse feita uma reforma esse contexto não existe mais. Nossa sobrevivência dependerá (e muito) do conceito de sustentabilidade para sobrevivência no planeta.

No Capítulo I, os autores aportam sobre as tendências globais, cujos desafios da nova hiperconectividade apresentam elementos condicionantes às relações, cuja tarefa da educação se dá para preparar os alunos para se adequarem a este mundo futuro. É necessário adaptar-se ao mundo atual, observando a interconexão entre as várias tendências, porque estamos todos globalmente interconectados e interdependentes. A versatilidade que os estudantes necessitam ser preparados se dá para o alcance de seus objetivos. Nem sempre conseguiremos prever os avanços tecnológicos importantes. Por isso, é importante ter a clareza dos caminhos para se buscar essa versatilidade. Atualmente, nos deparamos com as críticas sobre as tecnologias estão focadas na tendência do vício e do isolamento social, com compreensões reduzidas de leitura. Por outro lado, há o empoderamento do acesso e a possibilidade de agir de forma consciente para refletir e adaptar-se às mudanças. Velocidade e precisão podem ser ensinadas ao lado das habilidades que devemos continuar ensinando, como as interpessoais. Quanto mais avanços tecnológicos crescentes, mais haverá demanda por pessoas que se destacam em tarefas criativas e interpessoais, isto é, urge pensar no progresso da tecnologia e na educação necessária para usá-la com eficácia.

Em seu Capítulo II, a obra versa sobre os objetivos da educação para o Século XXI, resgatando os objetivos de Maslow, quando criou a "hierarquia das necessidades", ou como conhecemos habitualmente, a "pirâmide de Maslow". Ao referendar sobre os objetivos sociais, como cidadãos membros de uma sociedade, temos o pertencimento enquanto seres humanos. Em se tratando de objetivos sociais para uma educação humana, é necessário refletir sobre a situação que geramos quando a educação fica para trás da tecnologia. $\mathrm{O}$ cuidado com as crianças, a socialização, a acreditação, a avaliação, os objetivos e currículos da educação são objetivos atinentes que servem de parâmetro para este pensar. Destacamos este último, presente ao longo do terceiro capítulo, porque ao se pensar o currículo, devemos refletir que "os estudantes devem estar preparados para as demandas do mundo, aprendendo conhecimentos úteis e relevantes, qualidades do caráter e estratégias do meta-aprendizado" (p. 43). É nesse sentido que os currículos necessitam despertar as competências necessárias para que os sujeitos adquiram saberes em sua profundidade e o analisem de maneira inteligente. Cabe à educação, avaliar com atenção a relevância do que ensinamos, com mecanismos integrados para manter o currículo atualizado com descobertas modernas, 
disciplinas tradicionais e ideias inovadoras, além de aspectos resultantes de personalização e adaptação, emergindo questões de como aprendemos melhor e quais tipos de aprendizado são mais necessários.

As habilidades criativas, propostas no Capítulo IV, abordam sobre o conhecimento que é aprendido ao ser criado e recriado. Os autores alertam para a falsa dicotomia que há em focar o ensino em habilidades e se distanciar do conhecimento. Um exemplo desta discussão está nos recém graduados, que nem sempre apresentam habilidades para realizar as atividades que seus empregadores propõem. É com o desafio da criatividade que tem sido considerado no meio acadêmico, uma inserção variada de conhecimento acerca do pensamento científico, do empreendedorismo, do design thinking. Quanto mais promover a criatividade, maior é reformulação do conhecimento e da resolução de problemas, o que requer cada vez mais habilidades de comunicação, colaboração e intervenção crítica.

No capítulo $\mathrm{V}$, a dimensão do caráter apresenta reflexões que estão presentes na educação desde a Antiguidade, os quais se configuram na ética, no fortalecimento da virtude e dos valores para uma vida equilibrada e próspera. Quando há o avanço da ciência e dos progressos globais, unem-se a eles cenários que são desafios a essas práticas. Um exemplo são os pesticidas e a energia nuclear, isto é, a ciência avança e com ela, o risco à vida, também. Para o desenvolvimento do caráter, os autores propõem seis qualidades capazes de reforçar este conceito: a curiosidade, a coragem, a resiliência, a ética, a liderança.

A dimensão do meta-aprendizado, discutido no Capítulo VI, apresenta a prática da reflexão para que o indivíduo seja capaz de aprender com seu aprendizado, interligando uma mentalidade de crescimento capaz de estimular e aprender adaptando o seu saber e comportamento com base em seus objetivos. Assim, o processo de "pensar sobre o pensamento", (p. 133), definido como meta-cognição, atinge um grau de autorreflexão sobre onde está, seu futuro, estratégias e resultados que se deseja alcançar. É a metacognição que poderá ser utilizada para entender a aplicação do conhecimento, da habilidade e qualidade do caráter para determinada aprendizagem. Para tanto, a metacognição envolve pensamentos de alto nível e de nível inferior, cujos processos mentais passam por determinados estágios. "Os estudantes com uma orientação para o aprendizado tendem a usar mais estratégias metacognitivas e atingir níveis mais altos de realização acadêmica” (p. 140).

No Capítulo VII, os autores inserem referenciais sobre o currículo e o desenvolvimento profissional. Partindo da premissa das quatro dimensões, a reflexão segue na linha dos objetivos da educação para os estudantes do Século XXI, os quais constroem conhecimentos, aprendem habilidades, qualificam o caráter e desenvolvem estratégias de metacognição. É neste enfoque que a aula passa a ter um olhar para a aprendizagem associada a projetos que desenvolvem a criatividade e partem de problematizações, que têm o uso de artefatos tecnológicos como suporte. Tais características citadas vão além de atividades expositivas por parte do professor. O conteúdo e a competência são os principais fatores, associados ao que a tecnologia permite. 
Em seu oitavo capítulo, também denominado como conclusão, os autores retomam os principais conceitos expostos ao longo da obra, sempre se reportando aos objetivos da educação e trazendo a questão de como ela pode ser mais eficiente para os estudantes do Século XXI. Por vezes, o atual sistema ainda propicia lacunas em termos de conhecimento e habilidades. Prosperar para este "futuro incerto", é desenvolver a base de caráter e de metacognição para que cada estudante possa ter essas estratégias consigo quando for necessário seu uso.

Com o olhar nas quatro dimensões da educação, o referencial teórico evidencia caminhos que são possíveis para tornar a educação cada vez mais próxima dos reais desafios que a imprevisibilidade do futuro nos traz. A partir do momento que ensinarmos nossos alunos a desenvolver essas dimensões, estarão com habilidades mais desenvolvidas para adaptar-se às novas e imprevisíveis situações que surgirão, num tempo chamado futuro. 